Tạp chí Khoa học và Công nghệ biển T12 (2012). Số 1. Tr 67 - 76

\title{
ẢNH HƯỞNG CỦA THỨC ĂN VÀ ĐÔ MẠN ĐẾN SINH TRƯỞNG VÀ TỶ LỆ SỐNG CÁ KHOANG CỔ ĐỎ (AMPHIPRION FRENATUS BREVOORT, 1856) DƯỚI 60 NGÀY TUỔI
}

\author{
TRẦ VĂN PHƯỚC, NGUYẼ̃N ĐİNH TRUNG, VÕ THÀNH ĐẠT \\ Trường Đại học Nha Trang
}

HÀ LÊ THỊ LộC

Viện Hải dương học, Nha Trang

\begin{abstract}
Tóm tắt: Nghiên cưu ảnh hưởng của thức ăn và độ mạnn lên sinh truởng và tỷ lệ sống của cá Khoang Cổ Đỏ được tiến hành tại Viện Hải duơng học Nha Trang tù tháng 3 đến tháng 6 năm 2009. Kết quả nghiên cứu cho thấy, thức ăn là tảo, luân trùng và copepoda giúp cá tăng truởng nhanh, tỷ lệ sống cao nhất $(75,5 \%)$ và có màu sắc gần màu tụ nhiên so với các loại thức ăn khác $(p<0,05)$. Độ mặn thích hợp cho cá phát triển dao động tù $15 \%$ đến 40\%, khoảng thich hợp nhất dao động tù 30\%o đến 40\%o (tỷ lệ sống > 96\%). Tuy nhiên, đây chỉ là nghiên cứu khảo sát ban đầu nên chúng ta cần có những nghiên cứu sâu hơn các yếu tố sinh thái đến sinh truởng, tỷ lệ sống và màu sắc của cá.
\end{abstract}

Tù khóa: ảnh hương, độ mặn, thức ăn, tỷ lệ sống, sinh trương

\section{MỞ ĐẦU}

Trong những năm gần đây, nghề nuôi cá cảnh có những bước phát triển mạnh và đặc biệt là cá cảnh biển do chúng có màu sắc sặc sỡ, hình dạng phong phú. Hầu hết các đối tượng cá cảnh biển đều được khai thác từ tự nhiên, rất ít từ sinh sản nhân tạo. Quá trình khai thác cá cảnh biển sẽ ảnh hưởng rất lớn đến nguồn lợi tự nhiên. Cá Khoang Cổ là nhóm cá rạn san hô, chúng có màu sắc tươi sáng và vẻ hài hước khi bơi nên chúng còn được gọi là cá hề. Hiện nay, cá Khoang Cổ đang được nuôi khá phổ biến làm cảnh ở các khu du lịch và nhiều hộ gia đình ở nước ta. Cá cảnh biển nước ta khai thác chủ yếu tập trung ở khu vực miền Trung và khu vực vịnh Thái Lan do có nhiều rạn san hô. Gần đây thị trường cá cảnh biển phát triển mạnh mẽ trong và ngoài nước, cá rạn san hô bị khai thác bừa bãi làm tăng nguy cơ cạn kiệt nguồn lợi sinh vật biển [1]. Vì vậy, xây dựng quy trình sinh sản nhân tạo cá Khoang Cổ Đỏ nhằm đa dạng hóa đối tượng nuôi góp phần phát triển nghề nuôi đáp ứng nhu cầu thị trường và bảo vệ, tái tạo nguồn lợi tự nhiên là rất cần thiết. 


\section{TÀI LIÊUU VÀ PHƯƠNG PHÁP NGHIÊN CƯU}

\section{Thời gian, địa điểm và đối tượng nghiên cứu}

Nghiên cứu được thực hiện từ tháng 3 đến tháng 6 năm 2009 tại Trại thí nghiệm nghiên cứu sản xuất giống nhân tạo thuộc Phòng Công nghệ nuôi trồng - Viện Hải dương học Nha Trang. Đối tượng nghiên cứu là cá Khoang Cổ Đỏ (Amphiprion frenatus Brevoort, 1856) có nguồn gốc từ sinh sản nhân tạo.

\section{Nội dung nghiên cứu}

Thử nghiệm ảnh hưởng của các loại thức ăn và độ mặn khác nhau đến sinh trưởng và tỷ lệ sống cá Khoang Cổ Đỏ (từ 1 đến 60 ngày tuổi).

\section{Phưong pháp thu thập và xủ̉ lý số liệu}

Thu thập số liệu thông qua số liệu thứ cấp: các báo cáo khoa học, tài liệu có liên quan, tạp chí khoa học trong và ngoài nước; các số liệu sơ cấp thông qua bố trí thí nghiệm, chăm sóc và quản lý, cân đo cá thí nghiệm.

Về nguồn nước thí nghiệm: Nước biển được bơm vào bể lắng, sau đó bơm nước từ bể lắng vào bể chứa và xử lý nước bằng Chlorine với nồng độ $30 \mathrm{ppm}$, giữ nước trong bể chứa 3 ngày. Kiểm tra dư lượng Chlorine trong nước và khử bằng Thiosulphat trước khi sử dụng.

Thí nghiệm 1: Ảnh hưởng của các loại thức ăn khác nhau đến sinh trưởng và tỷ lệ sống cá Khoang Cổ Đỏ (từ 1 đến 30 ngày tuổi), với 4 nghiệm thức: NT1 (Tảo tươi, luân trùng và nauplius artemia), NT2 (Tảo tươi, luân trùng và copepoda), NT3 (Tảo tươi và thức ăn tổng hợp) và NT4 (Tảo khô, luân trùng và nauplius artemia).

Bể thí nghiệm: bể kính có thể tích 15L

Mật độ thả cá: $30 \mathrm{con} / \mathrm{bể}$

Các loại thức ăn được sử dụng: Tảo tươi Nanochoropsis oculata với mật độ $10^{6}$ tế bào/mL, luân trùng Brachionus plicatilis với mật độ $5-7 \mathrm{con} / \mathrm{mL}$, Nauplius của artemia với mật độ $5-7 \mathrm{con} / \mathrm{mL}$, Copepoda với mật độ $5-7 \mathrm{con} / \mathrm{mL}$ và thức ăn tổng hợp với tỷ lệ $0,2 \mathrm{~g} / 1000$ cá thể.

Bố trí thí nghiệm: cá Khoang Cổ Đỏ sau khi nở (1 ngày tuổi) được chuyển vào các bể thí nghiệm, nước cấp chủ yếu của bể thí nghiệm từ bể ấp để cá không bị sốc do môi trường thay đổi, mỗi nghiệm thức lặp lại 3 lần. Chế độ chăm sóc ở 4 nghiệm thức là như nhau: hàng ngày siphon và thay nước khoảng $20-30 \%$ lượng nước trong bể, kiểm tra số lượng cá chết. Thời gian cho ăn: 4 lần/ngày vào $8 \mathrm{~h}, 10 \mathrm{~h} 30,14 \mathrm{~h}$ và $16 \mathrm{~h} 30$.

Thí nghiệm 2: Ảnh hưởng của độ mặn khác nhau đến sinh trưởng và tỷ lệ sống cá 
Khoang Cổ Đỏ (từ 15 đến 60 ngày tuổi), với 7 nghiệm thức: 5\%, 10\%o, 15\%o, 20\%o, 30\%o, 40\%o và đối chứng là nước biển (độ mặn dao động từ 33 - 35\%o).

Bể thí nghiệm: bể kính thể tích $15 \mathrm{~L}$

Mật độ thả cá: $25 \mathrm{con} / \mathrm{bể}$

Thức ăn: tảo tươi (mật độ tảo $10^{6}$ tế bào/mL), luân trùng Brachionus plicatilis với mật độ $5-7 \mathrm{con} / \mathrm{mL}$ và nauplius artemia (từ $2-3 \mathrm{con} / \mathrm{mL}$ ).

Bố trí thí nghiệm: cá Khoang Cổ Đỏ (15 ngày tuổi) được chuyển vào các bể thí nghiệm, mỗi thí nghiệm lặp lại 3 lần. Quản lý chăm sóc: siphon, vệ sinh bể và cấp thêm nước mới ở các bể thí nghiệm, cho ăn ngày 2 lần vào sáng và chiều.

Các thông tin cần thu thập: (1) Các yếu tố môi trường: Đo nhiệt độ bằng nhiệt kế rượu (độ chính xác $1^{\mathrm{oC}}$ ); độ mặn đo bằng khúc xạ kế (độ chính xác $1 \%$ ); $\mathrm{pH}$ đo bằng test $\mathrm{pH}$ cầm tay; $\mathrm{NO}_{3}{ }^{-}$đo bằng test $\mathrm{NO}_{3}{ }^{-}$; hàm lượng $\mathrm{Oxy}$ hòa tan $(\mathrm{DO})$ xác định bằng test so màu; (2) Tăng trưởng của cá (kích thước và khối lượng) và (3) Tỷ lệ sống của cá (\%)

Công thức tính toán và xủ lý số liệu:

- Tốc độ tăng trưởng chiều dài hàng ngày

$\mathrm{DGRL}=\frac{L e-L s}{\mathrm{t} 2-\mathrm{t} 1}(\mathrm{~mm} / \mathrm{ngày})$

- Mức tăng chiều dài tuyệt đối

$\mathrm{LG}=\mathrm{Le}-\mathrm{Ls}(\mathrm{mm})$

Trong đó: Ls là chiều dài đo lần trước, Le - chiều dài đo lần sau và $t_{2}-\mathrm{t}_{1}$ là khoảng thời gian giữa 2 lần đo (ngày).

- Tỷ lệ sống: $\mathrm{X}=\frac{A}{N} * 100(\%)$. Trong đó: A - số cá còn lại khi kết thúc thí nghiệm và $\mathrm{N}$ - tổng số cá ban đầu.

Số liệu được xử lý theo phương pháp thống kê sinh học trên phần mềm Microsoft Office Excel 2003.

\section{KẾT QUẢ NGHIÊN CÚU VÀ THẢO LUẬN}

\section{1. Ảnh hưởng của thức ăn đến sinh trưởng và tỷ lệ sống cá (dưới 30 ngày tuổi)}

Cá Khoang Cổ Đỏ 1 ngày tuổi được bố trí ngẫu nhiên vào 4 nghiệm thức. Hệ thống ăn ngay sau khi nở với 4 loại thức ăn như dưới đây (bảng 1). 
Bảng 1: Quá trình sử dụng thức ăn trong thí nghiệm

\begin{tabular}{|c|c|c|c|}
\hline Nghiệm thức & Loai thức ăn & 1 ngày tuổi $\quad 5$ ngày tuổi & 30 ngày tuổi \\
\hline \multirow{3}{*}{ NT1 } & Tảo tươi & & \\
\hline & Luân trùng & & \\
\hline & Nauplius artemia & & \\
\hline \multirow{3}{*}{ NT2 } & Tảo tươi & & \\
\hline & Luân trùng & & \\
\hline & Copepoda & & \\
\hline \multirow{2}{*}{ NT3 } & Tảo tươi & & \\
\hline & Thức ăn tổng hợp & & \\
\hline \multirow{3}{*}{ NT4 } & Tảo khô & & \\
\hline & Luân trùng & & \\
\hline & Nauplius artemia & & \\
\hline
\end{tabular}

- Một số yếu tố môi trường trong thí nghiệm:

Một số yếu tố môi trường trong thí nghiệm ảnh hưởng của thức ăn đến tỷ lệ sống và sinh trưởng của cá được thể hiện ở bảng 2 .

Bảng 2: Một số yếu tố môi trường trong thí nghiệm

\begin{tabular}{|c|c|c|c|c|c|}
\hline Nhiệt độ ${ }^{\left({ }^{(C)}\right)}$ & Độ mặn (\%o) & $\mathbf{p H}$ & $\begin{array}{c}\mathbf{O x y} \text { hoà tan } \\
(\mathbf{m g} / \mathbf{l})\end{array}$ & $\mathbf{N H}_{\mathbf{4}}{ }^{+}(\mathbf{m g} / \mathbf{l})$ & $\left.\mathbf{N O}_{\mathbf{3}}{ }^{-} \mathbf{m g} / \mathbf{l}\right)$ \\
\hline $26-28$ & $35-36$ & $7,9-8,3$ & $5,5-6,5$ & $0-0,1$ & $0-0,05$ \\
\hline
\end{tabular}

Nhìn chung, các yếu tố môi trường trong hệ thống bể thí nghiệm nằm trong giới hạn cho phép, thích hợp với sự phát triển của cá [3]. Tuy nhiên, ở nghiệm thức NT3 thì hàm lượng $\mathrm{NH}_{4}{ }^{+}$và $\mathrm{NO}_{3}{ }^{-}$có xu hướng tăng cao hơn các nghiệm thức khác.

- Anh hưởng của thức ăn đến tăng trương chiều dài cá:

Tăng trưởng chiều dài của cá chịu ảnh hưởng của nhiều yếu tố và trong đó thức ăn đóng vai trò quan trọng. Kết quả 4 nghiệm thức được thể hiện ở bảng 3 .

Bảng 3: Chiều dài (mm) của cá ở các nghiệm thức thức ăn khác nhau

\begin{tabular}{|c|c|c|c|c|}
\hline \multirow{2}{*}{$\begin{array}{c}\text { Tuổi } \\
\text { (ngày) }\end{array}$} & \multicolumn{4}{|c|}{ Nghiệm thức } \\
\cline { 2 - 5 } & NT1 & NT2 & NT3 & NT4 \\
\hline 1 & $4,60 \pm 0,00$ & $4,60 \pm 0,00$ & $4,60 \pm 0,00$ & $4,60 \pm 0,00$ \\
\hline 10 & $11,56 \pm 0,81^{\mathrm{a}}$ & $10,74 \pm 0,66^{\mathrm{a}}$ & $6,54 \pm 1,46^{\mathrm{b}}$ & $8,25 \pm 0,96^{\mathrm{c}}$ \\
\hline 15 & $15,06 \pm 1,29^{\mathrm{a}}$ & $14,80 \pm 0,63^{\mathrm{a}}$ & $9,80 \pm 1,57^{\mathrm{b}}$ & $12,50 \pm 1,29^{\mathrm{c}}$ \\
\hline 20 & $17,27 \pm 0,70^{\mathrm{a}}$ & $16,70 \pm 0,95^{\mathrm{a}}$ & $12,70 \pm 1,60^{\mathrm{b}}$ & $14,00 \pm 1,00^{\mathrm{bc}}$ \\
\hline 25 & $18,20 \pm 0,86^{\mathrm{a}}$ & $17,90 \pm 0,71^{\mathrm{a}}$ & $13,90 \pm 2,03^{\mathrm{b}}$ & $15,33 \pm 0,58^{\mathrm{c}}$ \\
\hline 30 & $19,00 \pm 0,74^{\mathrm{c}}$ & $18,50 \pm 0,71^{\mathrm{a}}$ & $14,50 \pm 2,99^{\mathrm{b}}$ & $16,50 \pm 1,00^{\mathrm{c}}$ \\
\hline
\end{tabular}


Ghi chú: Số liệu trình bày trong bảng là giá trị trung bình \pm độ lệch chuẩn. Số liệu cùng hàng có các chữ cái khác nhau thể hiện sai khác có ý nghĩa thống kê $(\mathrm{p}<0,05)$.

Kết quả ở bảng 3 cho thấy: kích thước cá ở NT3 nhỏ nhất so với cá ở 3 nghiệm thức còn lại $(\mathrm{p}<0,05)$ và cá ở nghiệm thức này có độ phân đàn lớn (độ lệch chuẩn lớn). Cá ở NT1 và NT2 có chiều dài lớn và đồng đều hơn so với 2 nghiệm thức còn lại. Điều này cho thấy thức ăn có ảnh hưởng đến tăng trưởng chiều dài của cá.

Bảng 4: Tốc độ tăng trưởng chiều dài cá ( $\mathrm{mm} / \mathrm{ngày)}$

\begin{tabular}{|c|c|c|c|c|}
\hline \multirow{2}{*}{ Tuổi (ngày) } & \multicolumn{4}{|c|}{ Nghiệm thức } \\
\cline { 2 - 5 } & NT1 & NT2 & NT3 & NT4 \\
\hline 10 & 0,77 & 0,68 & 0,22 & 0,41 \\
\hline 15 & 0,70 & 0,81 & 0,65 & 0,85 \\
\hline 20 & 0,44 & 0,38 & 0,58 & 0,30 \\
\hline 25 & 0,19 & 0,24 & 0,24 & 0,27 \\
\hline 30 & 0,16 & 0,12 & 0,12 & 0,23 \\
\hline
\end{tabular}

Chiều dài cá tăng nhanh đáng kể ở NT1 và NT2 so với NT3 có thể do chế độ thức ăn NT3 không có luân trùng và cá chưa quen với thức ăn tổng hợp trong thời gian đầu. NT4 cá tăng trưởng chậm hơn so với NT1 và NT2 có thể do NT4 sử dụng tảo khô nên chất lượng không tốt bằng tảo tươi nên làm giảm chất lượng artemia. Điều này một lần nữa chứng minh kết quả của Wootton (1995) về tác dụng của tảo tươi trong việc kích hoạt hệ men trong ruột của cá con để cá có thể bắt đầu tiêu hoá được lượng thức ăn tươi sống đưa từ ngoài vào như luân trùng, nauplius của artemia. Đồng thời tảo tươi sẽ là nguồn thức ăn cho luân trùng hoặc artemia trong môi trường nuôi.

Tốc độ tăng trưởng của cá lớn ở các nghiệm thức NT1, NT2 ở ngày tuổi thứ 15 trong khi đó ở nghiệm thức NT3, NT4 cá có tốc độ tăng trưởng lớn ở ngày tuổi thứ 15 và 20. Nhìn chung cá có tốc độ tăng trưởng lớn ở ngày tuổi thứ 15 và sau đó giảm dần.

- Anh hương của thức ăn đến tỷ lệ sống cá:

Tỷ lệ sống của cá con trong sinh sản nhân tạo phụ thuộc vào rất nhiều yếu tố như điều kiện môi trường sống, chất lượng đàn cá bố mẹ và đặc biệt là thức ăn. Thức ăn là yếu tố ảnh hưởng lớn nhất đến tỷ lệ sống của cá dưới 01 tháng tuổi.

Qua theo dõi cho thấy, cá thường chết nhiều vào tuần đầu tiên sau khi nở. Điều này tương tự với một số kết quả nghiên cứu trước đây đối với ấu trùng cá Khoang Cổ, tỷ lệ sống xấp xỉ $50 \%$ trong hai tuần đầu và chết cao nhất từ ngày thứ 2 và thứ 8 sau khi nở [2]. Tỷ lệ sống của cá con trong điều kiện thí nghiệm phụ thuộc vào nhiều yếu tố như chất lượng trứng, điều kiện môi trường bể ấp và bể nuôi ấu trùng. Tuy nhiên, kết quả nghiên cứu cho thấy các yếu tố môi trường (nhiệt độ, độ mặn, $\mathrm{pH}$, oxy hòa tan, $\mathrm{NH}_{3}{ }^{+}$và $\mathrm{NO}_{3}{ }^{-}$) đều nằm 
trong phạm vi giới hạn đối với cá nuôi (bảng 2), nguồn cá được lấy từ cùng một ổ trứng nên chất lượng trứng là như nhau. Do vậy sự khác nhau rõ rệt về tỷ lệ sống giữa các nghiệm thức là do ảnh hưởng bởi các loại thức ăn khác nhau.

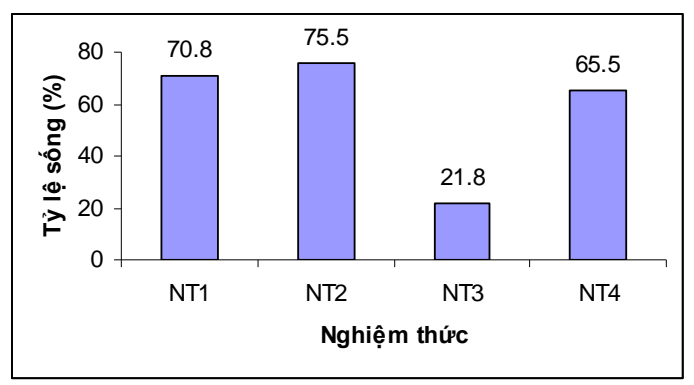

Hình 1: Tỷ lệ sống của cá ở các nghiệm thức (\%)

Từ hình 1 cho thấy tỷ lệ sống của cá trong các lô thí nghiệm có sự khác biệt rõ rệt, chia làm 2 nhóm: NT1, NT2 và NT4 có tỷ lệ sống cao hơn nhiều so với NT3 là 21,8\%. Cá Khoang Cổ Đỏ mới nở có xu hướng bắt mồi sống nên sự khác biệt trên là do NT1, NT2 và NT4 sử dụng luân trùng để cho cá ăn từ ngày đầu đến 5 ngày tuổi, NT3 sử dụng thức ăn tổng hợp ngay từ ngày đầu nên cá chưa quen thức ăn lạ. Cá chết nhiều trong 3 ngày đầu ở NT3 và quan sát trên kính hiển vi thì thấy không có thức ăn tổng hợp trong dạ dày cá, chỉ có một ít tảo. Điều này cho thấy cá ở NT3 chết do thiếu thức ăn vì cá chưa quen bắt mồi tĩnh và thức ăn không có liên tục trong môi trường sống của cá. Ở NT4 tỷ lệ sống cao $(65,5 \%)$, tảo khô có thể sử dụng thay cho tảo tươi làm thức ăn cho cá và artemia, copepoda, giúp chuẩn bị thức ăn cho cá dễ dàng hơn.

Từ kết quả trên cho thấy luân trùng là thức ăn cần thiết cho cá bột trong 5 ngày đầu, chúng có ảnh hưởng quyết định đến tỷ lệ sống của cá bột. Tảo tươi có vai trò ổn định môi trường bể nuôi, làm thức ăn cho luân trùng, copepoda và nauplius artemia, ngoài ra còn làm thức ăn trực tiếp cho cá.

- Anh hương của thức ăn đến màu sắc cá:

Ở NT2, cá có màu đỏ tươi đẹp nhất (giống màu tự nhiên), cá ở các nghiệm thức khác có màu cam nhạt hơn. Nguyên nhân là do NT2 sử dụng copepoda làm thức ăn để ương nuôi giống với thức ăn tự nhiên của cá.

Qua kết quả thí nghiệm thấy rằng luân trùng là thức ăn có ảnh hưởng quyết định đến tỷ lệ sống của cá trong những ngày đầu tiên. Để đạt được tỷ lệ sống cao và sinh trưởng tốt trong ương nuôi cá mới nở thì cần cung cấp cho cá luân trùng với mật độ khoảng 5 - 7 con/mL ngay từ ngày đầu đến ngày thứ 5 , sau đó cho cá ăn nauplius artemia hoặc copepoda những ngày tiếp theo. Nên bổ sung tảo tươi liên tục trong suốt quá trình nuôi, có 
thể sử dụng tảo khô để thay thế. Việc sử dụng thức ăn tươi sống trong quá trình ương nuôi tốt hơn sử dụng thức ăn tổng hợp vì thức ăn tươi sống cung cấp cho cá con những nguyên tố vi lượng cần thiết mà thức ăn tổng hợp không có, kích thích bắt mồi tốt hơn.

\section{2. Ảnh hưởng của độ mặn đến sinh trưởng và tỷ lệ sống cá}

Độ mặn là yếu tố sinh thái quan trọng đối với sinh trưởng và phân bố của các loài cá biển. Theo nghiên cứu của Hà Lê thị Lộc (2005) thì ngưỡng thích nghi của cá Khoang Cổ là từ $20 \%$ đến $45 \%$ (có tỷ lệ sống trên $50 \%$ ) và độ mặn thích hợp nhất cho cá nuôi là từ $25 \%$ o đến $40 \%$.

Thí nghiệm ảnh hưởng của độ mặn lên sinh trưởng và tỷ lệ sống của cá từ 15 ngày tuổi được bố trí với các thang độ mặn từ $5 \%$ đến $40 \%$ nhằm mục đích thử nghiệm mở rộng phạm vi độ mặn có thể nuôi được cá và xem xét quá trình sinh trưởng ở các độ mặn khác, giúp người nuôi chăm sóc cá tốt hơn.

- Một số yếu tố môi truờng trong thí nghiệm:

Các yếu tố môi trường trong thí nghiệm được thể hiện ở bảng 5 .

Bảng 5: Các yếu tố môi trường trong thí nghiệm

\begin{tabular}{|c|c|c|c|c|}
\hline Nhiệt độ $\left(\mathbf{t}^{\mathbf{0}} \mathbf{C}\right)$ & $\mathbf{p H}$ & $\mathbf{D O}(\mathbf{m g} / \mathbf{L})$ & $\mathbf{N O}_{\mathbf{3}}{ }^{-}(\mathbf{m g} / \mathbf{L})$ & $\mathbf{N H}_{\mathbf{4}}{ }^{+}(\mathbf{m g} / \mathbf{L})$ \\
\hline $24-28$ & $7,9-8,4$ & $5,5-6,5$ & $0-0,05$ & $0-0,2$ \\
\hline
\end{tabular}

Các yếu tố môi trường được quản lý tương đối ổn định và dao động nằm trong khoảng thích hợp cho sự phát triển của cá [3].

Hàm lượng DO có suy giảm sau một thời gian nuôi nhưng vẫn ổn định ở mức cao (DO $>5 \mathrm{mg} / \mathrm{L}$ ), khi DO giảm thì tiến hành sục khí nên hàm lượng DO ổn định hơn.

Hàm lượng nitrat tăng lên theo thời gian nuôi do tăng quá trình trao đổi chất của cá và tăng lượng chất thải do cá lớn. Tuy nhiên, hàm lượng nitrat vẫn nằm trong giới hạn cho phép.

- Anh hương của độ mặn lên sinh trưởng của cá:

Tăng trưởng của cá ở các nghiệm thức được thể hiện ở bảng 6 .

Chiều dài trung bình cá Khoang Cổ Đỏ ở các nghiệm thức 30\%o, 35\%, 40\%o lớn hơn so với chiều dài trung bình của cá ở các nghiệm thức $10 \%$, $15 \%$ và $20 \%$ ở ngày tuổi thứ 25 và $35(p<0,05)$ (bảng 6$)$. Cá có tốc độ tăng trưởng cao ở các nghiệm thức $30 \%$, 35\%, $40 \%$ o ở ngày tuổi thứ 25 và 35 so với các nghiệm thức $10 \%$, 15\%o và $20 \%$ (bảng 7 ). 
Bảng 6: Chiều dài cá Khoang Cổ Đỏ theo tuổi ở các nghiệm thức (mm)

\begin{tabular}{|c|c|c|c|c|c|}
\hline \multirow{2}{*}{$\begin{array}{l}\text { Nghiệm } \\
\text { thức }\end{array}$} & \multicolumn{5}{|c|}{ Tuổi (ngày) } \\
\hline & 15 & 25 & 35 & 45 & 60 \\
\hline $5 \%$ & $13.2 \pm 0.30^{\mathrm{a}}$ & & & & \\
\hline $10 \%$ & $13.2 \pm 0.30^{\mathrm{a}}$ & $13.67 \pm 0.159^{\mathrm{a}}$ & & & \\
\hline $15 \%$ & $13.2 \pm 0.30^{\mathrm{a}}$ & $14.73 \pm 0.248^{b}$ & $17.67 \pm 0.287^{\mathrm{a}}$ & $19.21 \pm 0.252^{\mathrm{a}}$ & $22.57 \pm 0.196^{\mathrm{ab}}$ \\
\hline $20 \%$ & $13.2 \pm 0.30^{\mathrm{a}}$ & $14.53 \pm 0.291^{b}$ & $18.33 \pm 0.421^{\mathrm{ab}}$ & $19.07 \pm 0.241^{\mathrm{a}}$ & $21.90 \pm 0.273^{\mathrm{ab}}$ \\
\hline $30 \%$ & $13.2 \pm 0.30^{\mathrm{a}}$ & $15.73 \pm 0.396^{\mathrm{c}}$ & $18.57 \pm 0.202^{\mathrm{b}}$ & $19.42 \pm 0.248^{\mathrm{a}}$ & $22.67 \pm 0.273^{b}$ \\
\hline $35 \%$ & $13.2 \pm 0.30^{\mathrm{a}}$ & $15.73 \pm 0.284^{c}$ & $18.75 \pm 0.281^{b c}$ & $19.09 \pm 0.159^{\mathrm{a}}$ & $21.80 \pm 0.301^{\mathrm{a}}$ \\
\hline $40 \%$ & $13.2 \pm 0.30^{\mathrm{a}}$ & $15.67 \pm 0.270^{c}$ & $19.53 \pm 0.256^{\mathrm{c}}$ & $19.69 \pm 0.194^{\mathrm{a}}$ & $22.57 \pm 0.298^{\mathrm{ab}}$ \\
\hline
\end{tabular}

Ghi chú: Số liệu trình bày trong bảng là giá trị trung bình \pm sai số chuẩn. Số liệu cùng cột có các chữ cái khác nhau thể hiện sai khác có ý nghĩa thống kê $(\mathrm{p}<0,05)$.

Bảng 7: Tốc độ tăng trưởng chiều dài của cá Khoang Cổ Đỏ (mm/ngày)

\begin{tabular}{|c|c|c|c|c|c|}
\hline \multirow{2}{*}{ Chỉ tiêu } & \multirow{2}{*}{ Độ mặn (\%o) } & \multicolumn{4}{|c|}{ Tuổi (ngày thứ) } \\
\cline { 2 - 6 } & & $\mathbf{2 5}$ & $\mathbf{3 5}$ & $\mathbf{4 5}$ & $\mathbf{6 0}$ \\
\hline \multirow{3}{*}{ DGR (mm/ngày) } & 10 & 0,04 & & & \\
\cline { 2 - 6 } & 15 & 0,15 & 0,29 & 0,15 & 0,22 \\
\cline { 2 - 6 } & 20 & 0,13 & 0,38 & 0,07 & 0,18 \\
\cline { 2 - 6 } & 30 & 0,25 & 0,28 & 0,08 & 0,21 \\
\cline { 2 - 6 } & 35 & 0,25 & 0,30 & 0,03 & 0,18 \\
\hline
\end{tabular}

Bảng 7 cho thấy tốc độ tăng trưởng chiều dài của cá cao ở ngày tuổi thứ 35 và thấp nhất ở ngày tuổi thứ 45 . Ở nghiệm thức $10 \%$ thì tốc độ tăng trưởng chiều dài rất thấp 0,04 $\mathrm{mm} /$ ngày do cá thích nghi kém ở độ mặn này, cá tốn nhiều năng lượng để điều hòa áp suất thẩm thấu nên tăng trưởng chậm. Ở ngày tuổi thứ 25 thì cá ở nghiệm thức $15 \%$ và $20 \%$ o đang trong quá trình thích nghi nên có tốc độ tăng trưởng chậm hơn so với cá nghiệm thức có độ mặn cao.

- Anh hương của độ mặn đến tỷ lệ sống của cá:

Nghiệm thức 5\%o, cá 15 ngày tuổi chết hết sau 3 ngày thí nghiệm. 
Nghiệm thức $10 \%$, cá chết hoàn toàn sau 13 ngày nuôi thí nghiệm (cá 28 ngày tuổi). Từ ngày đầu thí nghiệm đến ngày thứ 10 thì cá chỉ chết rải rác. Ngày thứ 11 , cá có các biểu hiện khác thường: cá không tụ đàn ở góc bể, cá bơi lờ đờ trên mặt nước, một số cá thể nằm lắng đáy, cá trong bể hầu như bỏ ăn và sang ngày thứ 12 thì chết hơn nữa, các cá thể còn lại rất yếu và sang ngày thứ 13 thì chết toàn bộ số cá còn lại.

Ở các nghiệm thức $15 \%$, 20\%o, 30\%o, 35\%o và $40 \%$ o thì tỷ lệ sống cao $\geq 92 \%$. Cá chết trong khoảng 10 ngày đầu thí nghiệm, sau giai đoạn này đến kết thúc thí nghiệm thì cá chết rất ít.

Từ các kết quả về tỷ lệ sống và sinh trưởng của cá Khoang Cổ Đỏ ở các độ mặn khác nhau thì ta có thể nuôi cá ở độ mặn từ $15 \%$ oến $40 \%$, cá đạt tỷ lệ sống cao ( $\geq$ $92 \%$ ) và có tốc độ tăng trưởng gần như nhau, thích hợp nhất là từ $30 \%$ đến $40 \%$. Trong quá trình nuôi không nên để độ mặn giảm xuống dưới 15\%o sẽ ảnh hưởng đến sức khỏe cá.

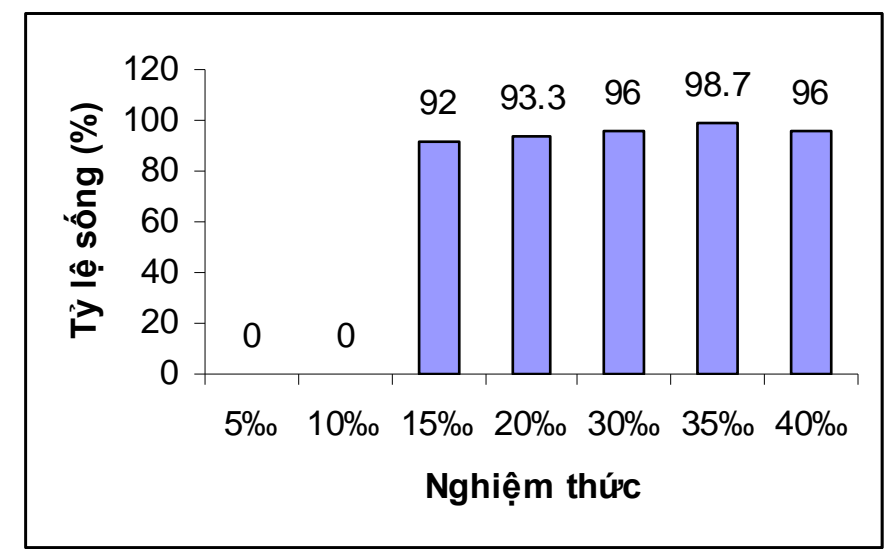

Hình 2: Tỷ lệ sống của cá ở các nghiệm thức (\%)

\section{KẾT LUẬN VÀ KIẾN NGH!̣}

- Kết quả thử nghiệm ảnh hưởng của thức ăn và độ mặn đến sinh trưởng và tỷ lệ sống cá Khoang Cổ Đỏ (dưới 60 ngày tuổi) cho thấy, thức ăn là tảo tươi, luân trùng và copepoda giúp cá dưới 30 ngày tuổi tăng trưởng nhanh hơn các loại thức ăn khác ( $\mathrm{p}<$ $0,05)$, có tỷ lệ sống lớn nhất $(75,5 \%)$ và cá có màu sắc đẹp gần giống với cá ngoài tự nhiên.

- Độ mặn thích hợp cho ương nuôi cá (từ 15 đến 60 ngày tuổi) từ $15 \%$ đến $40 \%$, thích hợp nhất trong khoảng 30 - 40\%o và có tỷ lệ sống cao ( $\geq 96 \%)$. 
- Trên đây chỉ là nghiên cứu khảo sát ban đầu, cho nên cần có những nghiên cứu sâu hơn các yếu tố sinh thái đến sinh trưởng, tỷ lệ sống và màu sắc của cá Khoang Cổ Đỏ.

\section{TÀI LIỆU THAM KHẢO}

1. Đào Tấn Hổ và cộng tác viên, 2001. Thành phần hội sinh giữa Hải Quỳ và cá Khoang Cổ ở vịnh Nha Trang. Tuyển tập báo cáo khoa học Hội nghị Khoa học Biển Đông 2000. NXB. Nông nghiệp TP. Hồ Chí Minh.

2. Hà Thị Lê Lộc, 2002. Một số đặc điểm dinh dưỡng của cá Khoang Cổ (Amphiprion clackii). Báo cáo khoa học lưu trữ tại Viện Hải dương học Nha Trang, Khánh Hòa.

3. Hà Thị Lê Lộc, 2005. Nghiên cứu cơ sở sinh thái, sinh học phục vụ cho sinh sản nhân tạo cá Khoang Cổ (Amphiprion sp) vùng biển Khánh Hòa. Luận văn tiến sĩ sinh học, Viện Hải dương học Nha Trang, Khánh Hòa.

4. Wootton R. J, 1995. Ecology of Teleost Fishes. Chapman \& Hall. 404p.

\section{THE EFFECTS OF FEED AND SALINITY ON AMPHIPRION FRENATUS BREVOORT, 1856 GROWTH AND SURVIVAL RATE (LESS THAN 60 DAYS OF AGE)}

\section{TRAN VAN PHUOC, NGUYEN DINH TRUNG, VO THANH DAT, HA LE THI LOC}

Summary: The study on the effect of feed and salinity on Amphiprion frenatus growth and survival rate was carried out at Nha Trang Institute of Oceanography from March to June, 2009. The results showed that the feed was Nanochoropsis oculata, Brachionus plicatilis and Copepoda had a significant effect on the growth, survival rate $(75.5 \%)$ and colour of fish ( $p<$ 0.05). The salinity for fish growth was from 15ppt to 40ppt, especial the best growth was from 30ppt to 40ppt (survival rate over 96\%). However, that was only the first research so we have research into ecology factors effect on growth, survival rate and colour of fish.

Keywords: effect, salinity, feed, survival rate, growth.

Ngày nhận bài: 15 - 10 - 2010

Nguò̀i nhận xét: PGS. TS. Nguyễn Chu Hồi 